\title{
Analisa Keandalan Struktur Akibat Beban Gelombang Pada Kapal Perang Tipe Corvette
}

\author{
Teguh Tri Efendi, Aries Sulisetyono, dan Teguh Putranto \\ Jurusan Teknik Perkapalan, Fakultas Teknologi Kelautan, Institut teknologi Sepuluh Nopember (ITS) \\ Jl. Arief Rahman hakim, Surabaya 60111 Indonesia \\ e-mail : sulisea@na.its.ac.id, theories@na.its.ac.id
}

\begin{abstract}
Abstrak-Kapal perang merupakan kapal yang digunakan untuk kepentingan militer demi mempertahankan kedaulatan bangsa. Untuk menunjang itu semua, salah satu hal yang harus diperhatikan adalah dalam mendesain strukur kapal. Penelitian ini dimaksudkan untuk mengkaji desain struktur kapal perang untuk daerah operasional perairan terbuka di Indonesia yang memiliki tinggi rata-rata gelombang sekitar 3-6 m. Pembahasan ini dititikberatkan pada perhitungan nilai keandalan struktur yang diakibatkan oleh tegangan dari beban gelombang. Analisa dilakukan dengan memodelkan kapal menggunakan Software Poseidon dan Software untuk menghitung RAO untuk mendapatkan nilai tegangan. Metode simulasi Monte Carlo digunakan untuk menetukan nilai keandalan Strukur. Variasi dilakukan terhadap tinggi gelombang dan sudut hadap. Dari hasil perhitungan Simulasi Monte Carlo didapatkan nilai keandalan Struktur pada tinggi gelombang $3 \mathrm{~m}$ sebesar 0,999 dan probabilitas kegagalan sebesar 0.001 , tinggi gelombang $4 \mathrm{~m}$ sebesar 0,998 dan probabilitas kegagalan sebesar 0.002 , tinggi gelombang $5 \mathrm{~m}$ sebesar 0,955 dan probabilitas kegagalan sebesar 0.045 , dan tinggi gelombang $6 \mathrm{~m}$ sebesar 0,805 dan probabilitas kegagalan sebesar 0.195 .
\end{abstract}

Kata kunci-Kapal Perang, tegangan , simulasi monte carlo, dan Keandalan Struktur.

\section{PENDAHULUAN}

$\mathrm{K}$ APAL perang merupakan kapal yang digunakan untuk kepentingan militer atau angkatan bersenjata demi mempertahankan kedaulatan bangsa. Dengan dilengkapinya persenjataan yang lengkap, kecepatan yang tinggi serta maneuver yang baik maka akan membuat kapal perang di Indonesia semakin baik dalam mempertahankan kedaulatan bangsa serta kejayaan maritim Indonesia. Akan tetapi dengan semakin tingginya kecepatan pada kapal perang yang khususnya pada kapal perang korvet, maka akan mempengaruhi keandalan dari struktur yang ada pada kapal tersebut. Selain itu, pengawasan sumber daya laut terhadap tindakan pencurian menjadi salah satu tolok ukur bahwa negara dapat mempertahankan kedaulatan maritimnya. Kegiatan operasi militer yang dilakukan oleh TNI perlu didukung dengan peralatan dan persenjataan yang canggih. Kebutuhan kapal perang tentunya dapat mendukung kinerja TNI untuk menjalankan operasi militernya. Kondisi perairan dengan ketinggian gelombang tertentu dapat menyebabkan kapal mengalami Kegagalan struktur yang dapat mengakibatkan kerusakan konstruksi pada bagian kapal.

Oleh karena itu, salah satu hal yang harus diperhatikan di dalam mendesain sebuah kapal perang, yaitu kemampuan di dalam melakukan sebuah penyerangan yang bertujuan untuk mempertahankan sesuatu. Salah satunya ialah, dengan menganalisa pembebanan yang diakibatkan oleh beban gelombang ataupun peralatan persenjtaan yang berfungsi untuk memberikan serangan ataupun pertahanan. Untuk analisa selanjutnya bisa dikatakan sangat penting, ialah analisa dari deck load, sehingga kapal memiliki tingkat keandalan yang tinggi selama waktu operasinya.

Berdasarkan latar belakang diatas maka perlu dilaksanakannya studi literatur untuk memahami analisa struktur konstruksi berbasis keandalan. Pada penelitian kali ini dilakukan analia keandalan struktur akibat beban gelombang regular pada kapal perang tipe corvette.

\section{DASAR TEORI}

\section{A. Konsep Keandalan}

Di dalam desain struktur kapal atau anjungan lepas pantai, tidak ada parameter perancangan dan kinerja operasi yang dapat diketahui dengan pasti. Hal ini karena tidak ada seorang pun yang mampu memprediksi kepastian atau ketidakpastianvatas suatu kejadian tertentu [1] .

Oleh karena itu, dalam setiap perancangan pasti mengandung ketidakpastian yang pada akhirnya menimbulkan ketidakandalan dalam suatu tingkatan tertentu. Keandalan sebuah komponen atau sistem adalah peluang komponen atau sistem tersebut untuk memenuhi tugas yang telah ditetapkan tanpa mengalami kegagalan selama kurun waktu tertentu apabila dioperasikan dengan benar dalam lingkungan tertentu [2].

\section{B. Konsep Ketidakpastian}

Pada struktur konstruksi yang modern tentunya isu keamanan merupakan aspek yang paling utama dalam pendesainan. Isu keamanan dalam analisa struktur adalah berkaitan denngan keakurasian dalam hal mendifinisikan ketidakpastian dalam hal pemodelan computer, pembebanan, geometri, proses produksi dan operasional [3].

\section{Simulasi Monte Carlo}

Simulasi Monte Carlo adalah salah satu metode yang dapat digunakan untuk menganalisis keandalan struktur. Ketika suatu sistem mengandung variable atau parameter yang memiliki nilai random, atau mengandung peubah acak, maka metode simulasi Monte Carlo dapat digunakan. Unsur pokok dalam simulasi Monte Carlo adalah penggunaan random number generator (RNG). 
Prinsipnya, sampel yang diambil berdasarkan RNG tadi akan dipakai sebagai masukan ke dalam fungsi kinerja $\mathrm{FK}(\mathrm{x})$, dan harga $\mathrm{FK}(\mathrm{x})$ kemudian dihitung. Misalnya untuk suatu fungsi kinerja tertentu, setiap $\mathrm{FK}(\mathrm{x})>0$, maka sistem atau komponen dianggap gagal. Jika jumlah sampel tersebut adalah $\mathrm{N}$, maka dicatat jumlah kejadian $\mathrm{FK}(\mathrm{x})>0$ sejumlah $\mathrm{n}$ kali. Dengan demikian maka peluang kegagalan sistem/komponen yang sedang ditinjau adalah perbandingan antara jumlah kejadian gagal dengan jumlah kejadian yang dilakukan [2].

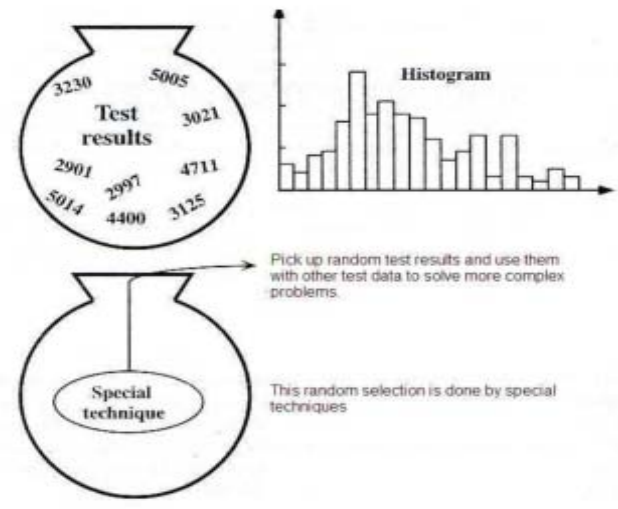

Gambar 2.1 Skematik metode Monte Carlo [5]

\section{Kapal perang tipe Corvette}

Korvet merupakan jenis kapal perang yang lebih kecil dari fregat dan lebih besar dari kapal patroli pantai, walaupun banyak desain terbaru yang menyamai fregat dalam ukuran dan tugas. Biasanya dimasukan kategori sebagai kapal patroli yang mampu melakukan operasi sergap dan serbu secara mandiri [4]

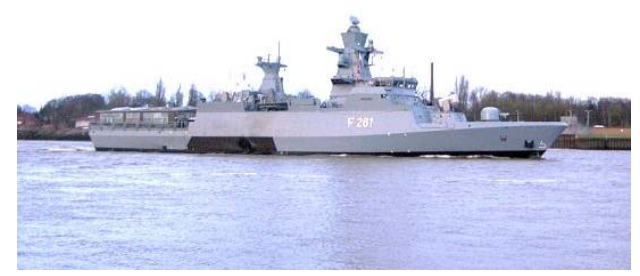

Gambar 2.2 kapal corvette

Gambar 2.2 merupakan salah satu contoh dari bentuk kapal perang tipe Corvette.

\section{E. Distrubusi WEIBULL}

Distribusi weibull adalah persaman yang biasanya digunakan untuk mengetahui suatu objek berfungsi sebagaimana mestinya atau tidak. Bisa dikatakan bahwa distribusi ini dapat menangani maslaah-masalah yang menyangkut lama waktu suatu objek dapat bertahan. Berikut rumus yang digunakan pada distribusi weibull. [2].

$$
F(x)=1-\exp \left(-\left(\frac{x-\gamma}{\beta}\right)^{\alpha}\right)
$$

\section{F. Tegangan}

Pada suatu penampang, gaya-gaya yang bekerja pada luasan umumnya sangat kecil (infinitesimal areas) pada penampang tersebut bervariasi baik dalambesar maupun arahnya. Gaya dalam merrupakan resultan dari gaya-gaya padabluasan yang sangat kecil ini. Instensitas gaya menentukan kemampuan suatu struktur atau material dalam menerima beban (kekuatan) disamping mempengaruhi sifat-sifat kekakuan maupun stabilitas [6]. Apabila dijabarkan dalam rumus adalah sebagai berikut :

$$
\begin{aligned}
& \quad \sigma=\mathrm{F} / \mathrm{A} \\
& \text { dengan : } \\
& \sigma: \text { Tegangan }\left(\mathrm{N} / \mathrm{m}^{2}\right) \\
& \mathrm{F} \text { : gaya }(\text { Newton}) \\
& \text { A : luas }\left(\mathrm{m}^{2}\right)
\end{aligned}
$$

\section{METODOLOGI PENELITIAN}

\section{A. Pengumpulan data dan Studi literatur.}

Studi literatur dilakukan dengan mempelajari berbagai bahan acuan seperti jurnal, buku dan referensi lain seperti Tugas Akhir sebelumnya. Studi literatur bertujuan untuk membantu dalam memahami dan menganalisis permasahalan pada penelitian ini. Selain itu juga dilakukan penelusuran literatur untuk mendapatkan data penunjang.

\section{B. Menetukan titik kritis}

Penentuan titik kritis dilakukan pada daerah dimana suatu struktur mempunyai nlai tegangan tertinggi apabila diberikan suatu beban kepada sttruktur tersebut.

\section{Uji Statistik untuk menentukan distribusi}

Dalam menetukan distribusi ini peneliti tidak sembarang memilih distribusi yang digunakan, melainkan dengan menggunakan bantuan software statistic. Dari software statistic tersebut kita dapat memsaukkan data berupa tegangan yang sudah didapat sebelumnya pada hasil model baru nanti kita bisa melihat distribusi mana yang sesuai dengan data yang peneliti masukkan.

\section{Menetukan Probalnility Density Function (PDF) tegangan}

Analisa PDF tegangan yang diperoleh dari tahap 4, dilakukan dengan menggunakan software statistic. Dari analisa tersebut akan diperoleh distribusi yang sesuai beserta parameter statistiknya.

\section{E. Menetukan persamaan moda}

Menetukan persamaan moda kegagalan untuk analisa keandalan struktur. Jadi moda kegagalan ini dijadikan sebagain acuan untuk mementukan apakah suatu struktur mengalami kegagalan atau tidak.

\section{F. Menentukan Random Variable}

Menentukan Random Variable dengan perintah yang ada pada excel yaitu dengan ketik perintah $=$ Rand() maka akan muncul angka yang diinginkan.Namun dibutuh pembuktian 
yang akurat untuk menentukan nilai Random Variable yaitu dengan rumus dari distribusi yang sudah didapatkan pada saat uji statistic sebelumnya.

\section{G. Simulasi Monte Carlo.}

Pada tahap ini dilakukan analisa kenadalan denagn metode Simulasi Monte Carlo. Sehingga pada tahap ini akan didapatkan nilai keandalan struktur.

\section{HASIL DAN PEMBAHASAN}

\section{A. Hasil Tegangan Kapal}

Merujuk pada tugas akhir [7] didaptkan hasil tegangan sebagai beirkut.

\begin{tabular}{|c|c|c|c|c|c|}
\hline \multirow{2}{*}{$\begin{array}{c}\text { Significant } \\
\text { Wave } \\
\text { Height }\end{array}$} & \multirow{2}{*}{$\begin{array}{l}\text { Wave } \\
\text { Heading }\end{array}$} & \multicolumn{2}{|c|}{ Tegangan(N/mm2) } & \multirow{2}{*}{$\begin{array}{l}\text { Tegangan } \\
\text { Ijin }(\mathrm{N} / \mathrm{mm} \mathbf{m})\end{array}$} & \multirow[b]{2}{*}{ Prosentase } \\
\hline & & Topdeck & Bottom & & \\
\hline \multirow{3}{*}{$\mathrm{Hs}=3 \mathrm{~m}$} & $\mu=90^{\circ}$ & 29.47 & 25.79 & 243.4 & $87.9 \%$ \\
\hline & $\mu=135^{\circ}$ & 118.52 & 103.71 & 243.4 & $51.3 \%$ \\
\hline & $\mu=180^{\circ}$ & 121.24 & 106.08 & 243.4 & $50.2 \%$ \\
\hline \multirow{3}{*}{$\mathrm{Hs}=4 \mathrm{~m}$} & $\mu=90^{\circ}$ & 40.67 & 35.58 & 243.4 & $83.3 \%$ \\
\hline & $\mu=135^{\circ}$ & 150.37 & 131.58 & 243.4 & $38.2 \%$ \\
\hline & $\mu=180^{\circ}$ & 172.37 & 150.83 & 243.4 & $29.2 \%$ \\
\hline \multirow{3}{*}{$\mathrm{Hs}=5 \mathrm{~m}$} & $\mu=90^{\circ}$ & 51.08 & 44.69 & 243.4 & $79.0 \%$ \\
\hline & $\mu=135^{\circ}$ & 170.43 & 149.12 & 243.4 & $30.0 \%$ \\
\hline & $\mu=180^{\circ}$ & 207.51 & 181.58 & 243.4 & $14.7 \%$ \\
\hline \multirow{3}{*}{$\mathrm{Hs}=6 \mathrm{~m}$} & $\mu=90^{\circ}$ & 60.50 & 52.94 & 243.4 & $75.1 \%$ \\
\hline & $\mu=135^{\circ}$ & 183.84 & 160.86 & 243.4 & $24.5 \%$ \\
\hline & $\mu=180^{\circ}$ & 231.89 & 202.90 & 243.4 & $4.7 \%$ \\
\hline
\end{tabular}

\section{B. Fit Distribusi}

Untuk menghitungan Keandalan struktur dibutuhkan distribusi yang akan digunakan ppada simulasi Monte Carlo. Salah satu yang dilakukan untuk menentukan distribui yang digunakan adalah dengan menggunakan Software statistic "Easyfit". Dengan ini peneliti memasukkan data hasil teganfan yang didapatkan. Kemudian dilakukan fit distrusi dan dari fit distribusi tersebut setelah peneliti memasukkan data hasil tegangan maka terdapat rangking distribusi yang dapat digunakan untuk menghitungan nilai Keandalan Struktur. Jadi dlam rangking tersebut peneliti ambil rangking yang paling tinggi untuk dijadikan sebagai distribusi yang paling tepat utnuk digunakan.

Tabel 4.2 rangking distribusi

\begin{tabular}{|c|c|c|c|c|c|c|c|}
\hline \multicolumn{8}{|c|}{ Goodness of Fit - Summary } \\
\hline \multirow[t]{2}{*}{ \# } & \multirow{2}{*}{ Distribution } & \multicolumn{2}{|c|}{$\begin{array}{c}\text { Kolmogorov } \\
\text { Smirnov }\end{array}$} & \multicolumn{2}{|c|}{$\begin{array}{c}\text { Anderson } \\
\text { Darling }\end{array}$} & \multicolumn{2}{|c|}{ Chi-Squared } \\
\hline & & Statistic & Rank & Statistic & Rank & Statistic & Rank \\
\hline 60 & Weibull & 0.16669 & 25 & 0.77126 & 4 & 0.29582 & 1 \\
\hline 59 & Weibull & 0.16669 & 24 & 0.77126 & 5 & 0.29582 & 2 \\
\hline 13 & Exponential & 0.27652 & 48 & 2.1117 & 41 & 0.51798 & 3 \\
\hline 38 & Log-Pearson 3 & 0.15146 & 13 & 0.81103 & 6 & 0.58926 & 4 \\
\hline 45 & Pareto 2 & 0.2853 & 51 & 2.2395 & 43 & 0.59864 & 5 \\
\hline 48 & Pearson 6 & 0.15247 & 14 & 0.93105 & 14 & 0.66765 & 6 \\
\hline 22 & Gen. Gamma & 0.1544 & 16 & 0.96948 & 19 & 0.69364 & 7 \\
\hline 31 & Kumaraswamy & 0.24 & 43 & 25.456 & 56 & 0.7 & 8 \\
\hline 20 & Gamma (3P) & 0.16131 & 20 & 0.93967 & 16 & 0.71313 & 9 \\
\hline 61 & Weibull (3P) & 0.15391 & 15 & 0.95439 & 18 & 0.76607 & 10 \\
\hline
\end{tabular}

\section{Hasil nilai Probability Density function}

Distribusi weibull yang sudah didapatkan dari proses fit distribusi digunakan untuk mementukan nilai Probability Density function. Nilai Probability Density function digunakan untuk menghitung dan mengkonversi bilangan acak yang digunakan pada perhitungan nilai Keandalan Struktur. Dari Probability Density function akan didapatkan nilai shape parameter $(\alpha)$ dan scale parameter $(\beta)$.

\section{Uji Statistik untuk Distribusi Weibull}

Sesuai dengan rumus weibull

$$
f(x)=1-\operatorname{sep}\left(-\left(\frac{x-\xi}{\beta}\right)^{n}\right)
$$

Dibutuhkan nilai X yang akan digunakan untuk menghitung nilai tegangan yang sudah dikonversikan untuk disimulasikan dengan simulasi monte carlo. Dimana nilai $F(X)$ adalah probabbilitas terambilnya suatu peluang, maka dari rumus tersebut dapat dijabarkan menjadi,

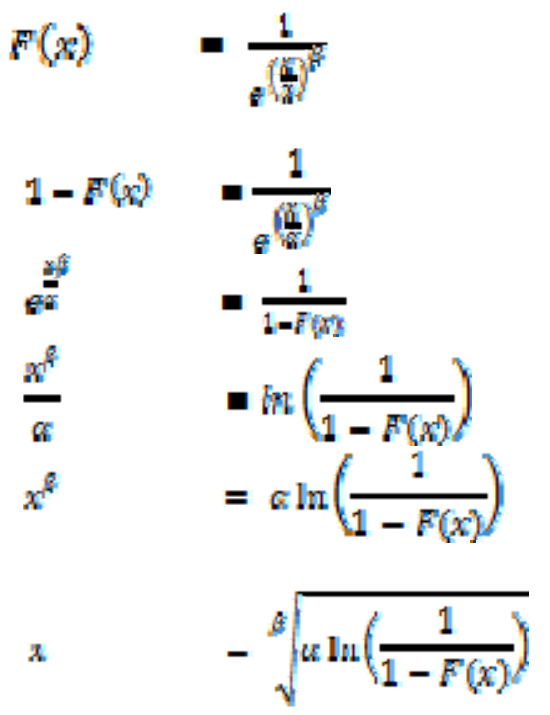

\section{E. Moda Kegagalan.}

Moda kegagalan meruapakan acuan ataupun patokan yang digunakan untuk menilai suatu produk atau obyek yang diteliti Moda kegagalan tersebut dapat diajadikan acuan, apabila nilai tegangan actual dibagi dengan tegangan ijin bernilai negative dan atau lebih dari satu maka nilai keandalan strukturnya bisa diakatakn gagal. Sedangkan, jika tegangan actual dibagi dengan tegangan ijin bernilai kurang dari sama dengan 1, maka nilai keandalan strukturnya bisa dikatan berhasil.

$$
\text { Modu Ragayslun }-\frac{\sigma a k E l a l}{\tau \text { ittn }} s 1
$$

\section{F. Nilai Acak}

Nilai acak disini berfungsi sebagai probabilitas yang digunakan dalam persamaan rumus weibull. Untuk melalukan pembuktian apakah rumus yang dipakai dengan nilai acak sudah sesuai apa tidak bisa dibuktikan dengan memsaukkan nilai tegangan sembarang.

\section{G. Analisa Keandalan Struktur dengan simulasi Monte carlo}

Dalam menghitung nilai keandalan struktur dibutuhkan moda kegagalan dan juga data acak yang sudah ditentukan di 
Sub Bab sebelumnya. Sehingga tinggal mengikuti algoritma perhitungan Keandalan Struktur.

Dalam menetukan nilai kenadalan struktur peneliti melakukan iterasi dari 10, 100, 1000, 10.000, 100.000, sampai 1.000 .000 . ietrasi ini dilakukan agar mendapatkan data yang valid dan mendapatkan nilai keandalan struktur yang benarbenar sesuai dengan apa yang sudah dikerjakan. Dan peneliti juga menyajikan nilai keandalan struktur dalam bentuk tabel dan juga kurva trendlaine untuk mempermudah peneliti dan pembaca dalam menganalisa hasil dari perhitungan nilai Keandlaan struktur.

Sesuai dengan algoritma perhitungan keandalan struktur dengan simulasi Monte Carlodidapatkan hasil nilai Keandalan struktur.

Tabel 4.1 Hasil keandalan struktur pada tinggi gelombang $3 \mathrm{~m}$

\begin{tabular}{|c|c|c|c|}
\hline \multicolumn{4}{|c|}{3 meter } \\
\hline No & Jumlah Simulasi & Pof & Keandalan \\
\hline 1 & 10 & 0.000000 & 1.000000 \\
\hline 2 & 100 & 0.000000 & 1.000000 \\
\hline 3 & 1000 & 0.000000 & 1.000000 \\
\hline 4 & 10000 & 0.000000 & 1.000000 \\
\hline 5 & 100000 & 0.000000 & 1.000000 \\
\hline 6 & 1000000 & 0.000001 & 0.999999 \\
\hline
\end{tabular}

Tabel 4.2 Hasil keandalan struktur pada tinggi gelombang $4 \mathrm{~m}$

\begin{tabular}{|c|c|c|c|}
\hline \multicolumn{4}{|c|}{4 meter } \\
\hline No & Jumlah Simulasi & Pof & Keandalan \\
\hline 1 & 10 & 0.000000 & 1.000000 \\
\hline 2 & 100 & 0.000000 & 1.000000 \\
\hline 3 & 1000 & 0.003000 & 0.997000 \\
\hline 4 & 10000 & 0.003000 & 0.997000 \\
\hline 5 & 100000 & 0.002280 & 0.997720 \\
\hline 6 & 1000000 & 0.002234 & 0.997766 \\
\hline
\end{tabular}

Tabel 4.3 Hasil keandalan struktur pada tinggi gelombang $5 \mathrm{~m}$

\begin{tabular}{|c|c|c|c|}
\hline \multicolumn{4}{|c|}{5 meter } \\
\hline No & Jumlah Simulasi & Pof & Keandalan \\
\hline 1 & 10 & 0.000000 & 1.000000 \\
\hline 2 & 100 & 0.030000 & 0.970000 \\
\hline 3 & 1000 & 0.040000 & 0.960000 \\
\hline 4 & 10000 & 0.046800 & 0.953200 \\
\hline 5 & 100000 & 0.044880 & 0.955120 \\
\hline 6 & 1000000 & 0.044978 & 0.955022 \\
\hline
\end{tabular}

Tabel 4.1 Hasil keandalan struktur pada tinggi gelombang $3 \mathrm{~m}$

\begin{tabular}{|c|c|c|c|}
\hline \multicolumn{4}{|c|}{6 meter } \\
\hline No & Jumlah Simulasi & Pof & Keandalan \\
\hline 1 & 10 & 0.000000 & 1.000000 \\
\hline 2 & 100 & 0.160000 & 0.840000 \\
\hline 3 & 1000 & 0.189000 & 0.811000 \\
\hline 4 & 10000 & 0.192000 & 0.808000 \\
\hline 5 & 100000 & 0.193740 & 0.806260 \\
\hline 6 & 1000000 & 0.194677 & 0.805323 \\
\hline
\end{tabular}

\section{KESIMPULAN DAN SARAN}

\section{A. Kesimpulan}

Dari analisis yang telah dilakukan maka didapatkan kesimpulan sebagai berikut :

1. Pada 10 kali simulasi memiliki nilai keandalan struktur sebesar 1.

2. Dilihat dari Trendline yang ada nilai Keandalan Struktur mengalami penurunan seiring dengan banyakya simulasi yang dilakukan.

3. Pada tinggi gelombang 3 meter nilai keandalan struktur 0.999 dan pada ketinggian 6 meter nilai keandalan strukturnya 0,805. Sehingga semakin tinggi beban gelomnang yang diberikan pada suatu kapal, maka Nilai Keandalan Struktur juga semakin Kecil.

4. Dari hasil perhitungan Simulasi Monte Carlo didapatkan nilai keandalan Struktur pada tinggi gelombang $3 \mathrm{~m}$ sebesar 0,999 dan probabilitas kegagalan sebesar 0.001, tinggi gelombang $4 \mathrm{~m}$ sebesar 0,998 dan probabilitas kegagalan sebesar 0.002 , tinggi gelombang $5 \mathrm{~m}$ sebesar 0,955 dan probabilitas kegagalan sebesar 0.045 , dan tinggi gelombang $6 \mathrm{~m}$ sebesar 0,805 dan probabilitas kegagalan sebesar 0.195 .

\section{B. Saran}

Adapun saran dalam penelitian kali ini :

1. Agar mendapatkan nilai Keandalan Struktur yang lebih akurat lagi, maka dibutuhkan Simulasi yang lain lagi sebagai pembanding dengan Simulasi Monte Carlo yang digunakan.

2. Variasi pembebanan yang diberikan sebaiknya lebih banyak lagi. Agar data yang diperoleh juga lebih akurat. Bisa diberikan lebih banyak tinggi gelombangnya, sudut hadap yang digunakan dan juga variasi kecepatan kapal.

3. Sebaiknya dalam penggunaan distribusi eibull data yang diolah termasuk data long term statistic bukan short term statistic.

\section{DAFTAR PUSTAKA}

[1] Baker, M. J., \& Wyatt, T. A. (1979). Methods of reability Analysis for jacket platform. London: Journal of Behavior of Offshore Structure.

[2] BKI. (1996). Rules For elding. Jakarta. 
[3] Choi, S. K., Grandhi, R. V., Canfield, \& Robert, A. (2006). Reliability Based Structure Design. London: Spinge Science.

[4] Perdana, D. I. (2013). Analisa Beban Gelombang pada Konstruksi Kapal Perang Tipe Corvette di Kondisi Perairan Indonesia. Surabaya: Tugas Akhir S1, Jurusan Teknik Perkapalan, Fakultas Teknologi Kelautan, Institut Teknologi Sepuluh Nopember.

[5] Nowak, A. S., \& Collin, K. R. (2000). Reliability of structure. Singapore: Mc Graw Hill.
[6] Rosyid, D. M. (2007). Pengantar Rekayasa Keandalan. Surabaya: Airlangga University Press.

[7] Arianto, P. Y. (2016). Analaisi tagngan AKibat Beban Gelombang Pada Struktur kapal Perang tipe Corvette. Surabaya: Tugas Akhir S1, Jurusan Teknik Perkapalan, Fakultas Teknologi Kelautan, Institut Teknologi Seouluh Nopember. 